\title{
Customized toric intraocular lens implantation for correction of extreme corneal astigmatism due to corneal scarring
}

This article was published in the following Dove Press journal:

Clinical Optometry

26 February 2010

Number of times this article has been viewed

\author{
R Bassily \\ J Luck \\ Ophthalmology Department, \\ Royal United Hospital, Combe Park, \\ Bath, UK
}

\begin{abstract}
A 76-year-old woman presented with decreased visual function due to cataract formation. Twenty-five years prior she developed right sided corneal ulceration that left her with 10.8 diopters (D) of irregular astigmatism at $71.8^{\circ}$ (steep axis). Her uncorrected visual acuity was 6/24 and could only ever wear a balanced lens due to the high cylindrical error. Cataract surgery was planned with a custom designed toric intraocular lens (IOL) with +16.0 $\mathrm{D}$ sphere inserted via a wound at the steep axis of corneal astigmatism. Postoperative refraction was $-0.75 /+1.50 \times 177^{\circ}$ with a visual acuity of $6 / 9$ that has remained unchanged at six-week follow-up with no IOL rotation. This case demonstrates the value of high power toric IOLs for the correction of pathological corneal astigmatism.
\end{abstract}

Keywords: intraocular lens, corneal ulceration, visual acuity, scarring

In the refractive correction of moderate corneal astigmatism various options are available such as keratotomy, laser in situ keratomileusis (LASIK), and photorefractive keratectomy (PRK). Toric intraocular lens implants (IOLs) have gained increasing popularity for the correction of regular corneal astigmatism as part of small-incision cataract surgery. They have proven efficacy, ${ }^{1}$ but until recently had limited dioptric powers available. Customized high cylindrical power toric IOLs may be a valuable option for the correction of higher degrees of corneal astigmatic error. They may be especially useful in the correction of pathologically-induced corneal astigmatism as well as naturally occurring astigmatism.

\section{Case report}

A 76-year-old woman was referred to the eye clinic with significant cataract in her right eye. She reported right sided corneal ulceration as part of her past ophthalmic history, some 25 years prior, which had left her with poor vision.

On examination the left eye was normal on slit lamp examination with an uncorrected visual acuity of 6/9. Her uncorrected visual acuity in the right was $6 / 24$, and could only wear a balance lens due to the ulceration causing such a high cylindrical error. There was an old vascularized scar superiorly on the right cornea (Figure 1), and significant nuclear and posterior subcapsular lens opacities. The rest of the ocular examination was unremarkable. Scheimfplug analysis (Pentacam; Oculus Optikgeräte GmbH, Wetzlar, Germany) demonstrated 10.8 diopters (D) of irregular corneal astigmatism at $71.8^{\circ}$ (steep axis) in the right eye (Figure 2). Cataract surgery with implantation of a custom-made toric IOL (Acri.Tec; Carl Zeiss, Hennigsdorf, Germany) was discussed with the patient and fully informed consent obtained. The corneal measurements and
Correspondence: R Bassily Ophthalmology Department, Royal United Hospital, Combe Park, Bath, BAI 3NG, UK Email ramybassily@hotmail.com 


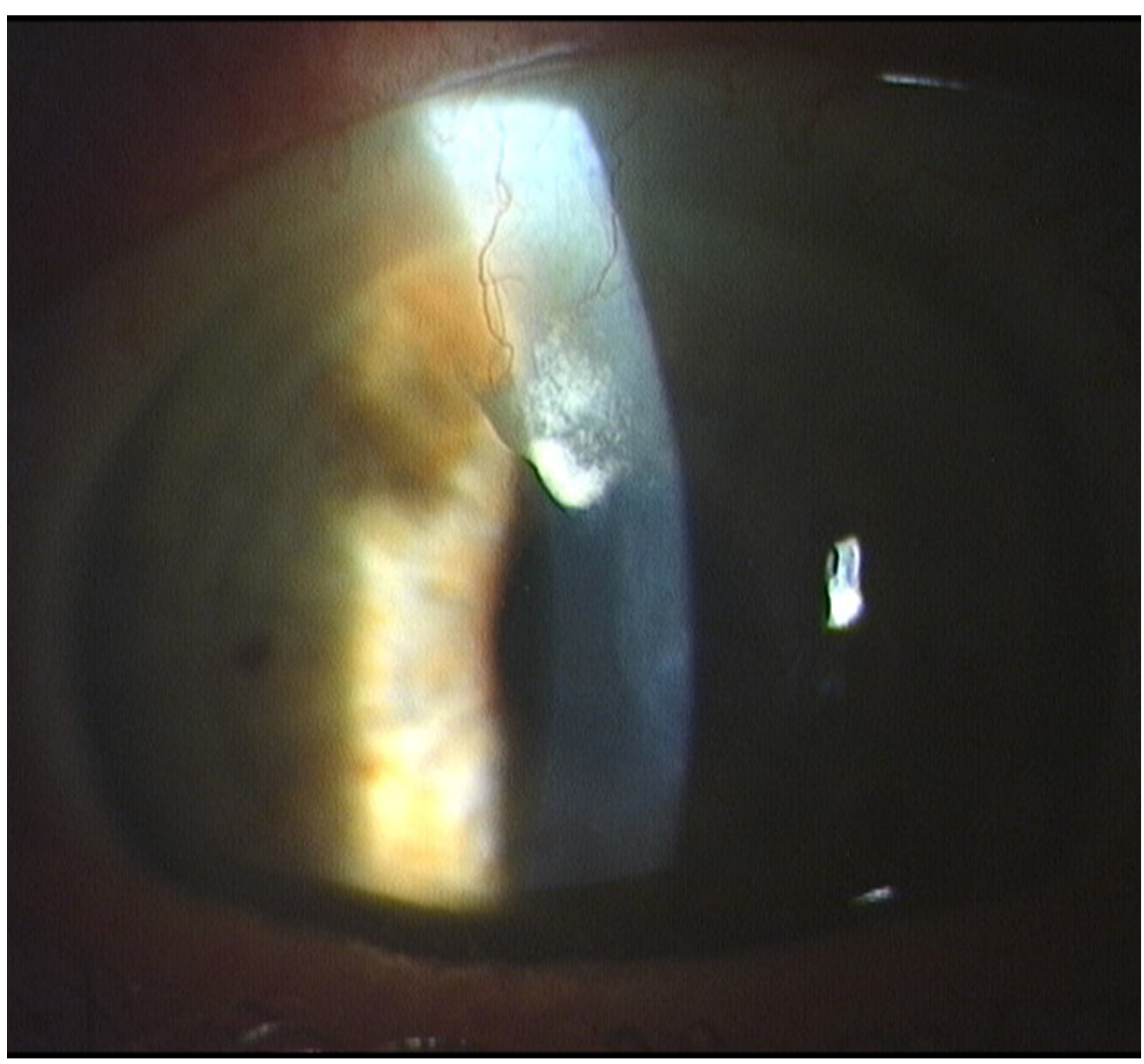

Figure I old vascularized scar on the right cornea.

refractive data were sent to the lens company for calculation of the appropriate lens implant. The suggested lens was a +16.0 D sphere with a +13.0 D cylinder.

The patient was marked preoperatively at the slit-lamp with a fine gentian marker pen using a plumb bob type instrument to ensure correct horizontal marking at the $90^{\circ}$ and $180^{\circ}$ axis. The patient underwent uncomplicated rightsided phacoemulsification cataract extraction. The wound was located in the steep axis of the corneal astigmatism. The lens implant was carefully oriented using a mask supplied by the company (Figure 3 ) as a reference, which adheres to the monitor of the microscope camera. Postoperative recovery was uneventful.
On review at six weeks postoperatively, the unaided acuity in the right eye was $6 / 18$, and the best spectacle-corrected acuity $6 / 9$ with a refraction of $-0.75 /+1.50 \times 177^{\circ}$.

\section{Discussion}

Use of toric IOLs for the correction of regular astigmatism has been demonstrated to be safe and effective. Problems with lens movement ${ }^{2}$ reducing or even cancelling out the cylindrical correction have largely disappeared with the advent of hydrophobic acrylic IOLs that demonstrate excellent stability within the capsular bag. ${ }^{1}$ The clinical effectiveness of toric lens implantation relies heavily on this rotational stability in the long term, and the higher the lens power, the more critical 


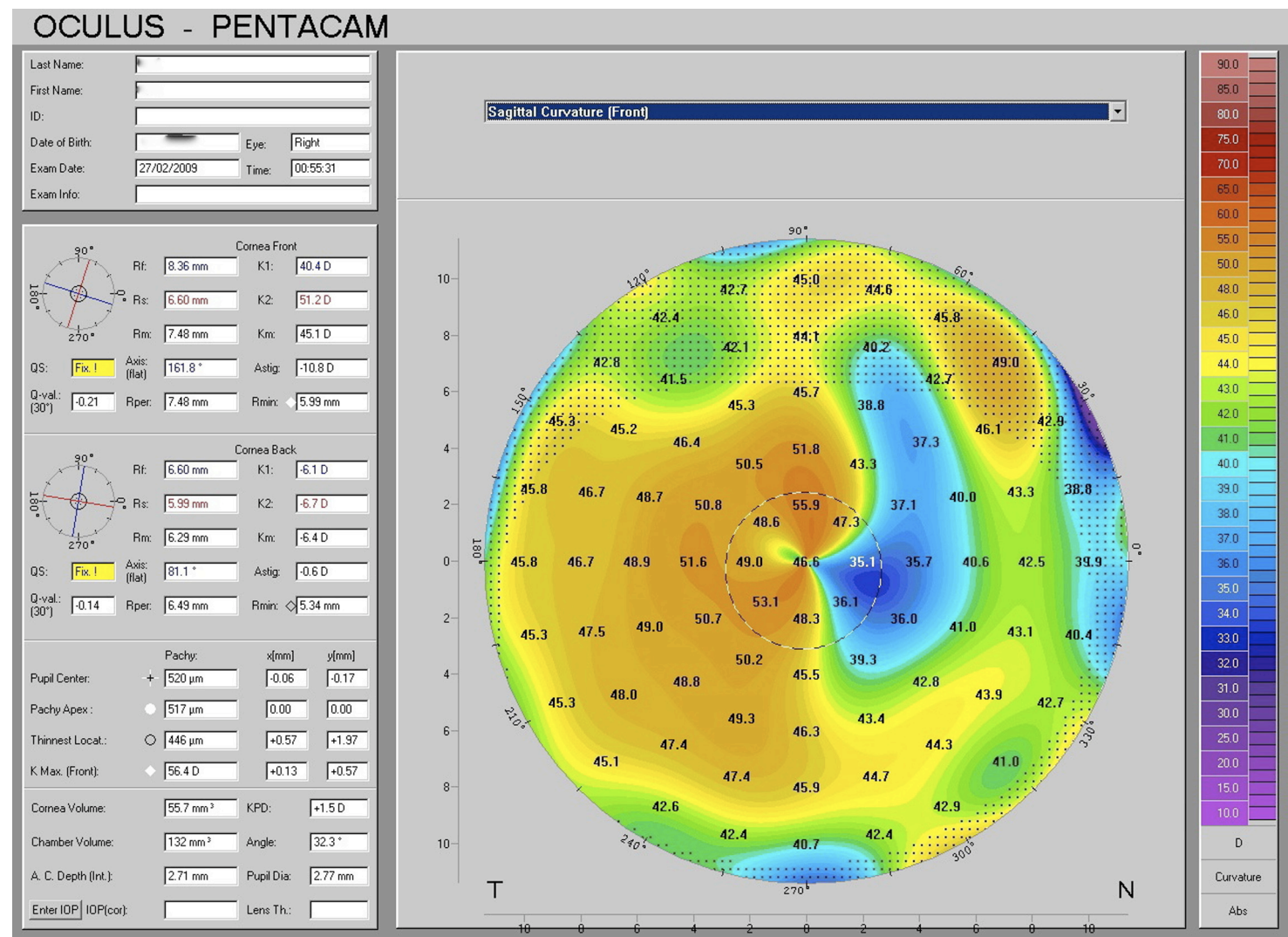

Figure 2 Pentacam image.

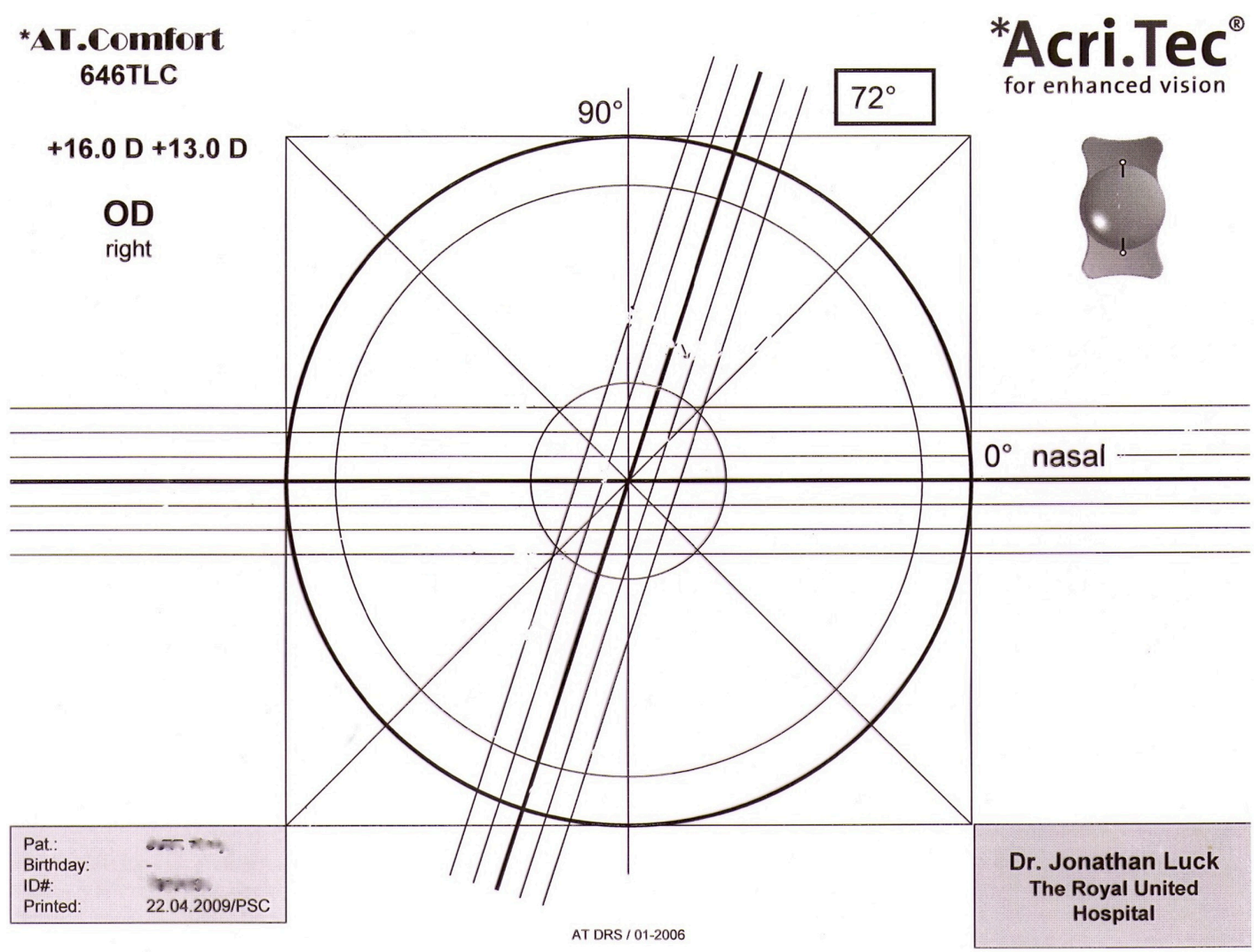

Figure 3 orientation of lens implant. 
it is that the lens demonstrates long-term rotational stability. It is well recognized that even a small deviation of the toric IOL from its intended axis can result in a large disruption to the astigmatic correction. ${ }^{3}$ For example, a deviation of $10^{\circ}$ can reduce the potential correction by $35 \%$. Previous authors have described the implantation of custom-made toric IOLs, albeit of differing design. Tehrani and colleagues used a high-power toric silicon IOL to correct post-keratoplasty astigmatism, although this case required additional implantation of a rigid spherical lens in the ciliary sulcus. ${ }^{4}$ A similar clinical situation in an aphakic patient was treated with a transcleral fixated IOL. ${ }^{5}$ Frohn described the use of a rigid polymethylmethacrylate (PMMA) IOL in a post-keratoplasty patient, with a good result. ${ }^{6}$

Our patient with extreme astigmatism had a good result from uncomplicated phacoemulsification and implantation of a high cylindrical power lens, of a modern one-piece design, into the capsular bag with low technical difficulty. We feel that modern custom-made toric IOL technology is promising in the treatment of high corneal astigmatism secondary to pathology that may not be amenable to other therapeutic approaches.

\section{Disclosures}

The author reports no conflicts of interest in this work.

\section{References}

1. Mendicute J, Irigoyen C, Aramberri J, Ondarra A, Montés-Micó R. Foldable toric intraocular lens for astigmatism correction in cataract patients. J Cataract Refract Surg. 2008;34(4):601-607.

2. Horn JD. Status of toric intraocular lenses. Curr Opin Ophthalmol. 2007;18(1):58-61.

3. Sanders DR, Grabow HB, Shepherd J. The toric IOL. In: Sutureless Cataract Surgery; An Evolution Toward Minimally Invasive Technique. Gills JP, Martin RG, Sanders DR, editors. Thorofare, NJ: Slack; 1992: 183-197.

4. Tehrani M, Stoffelns B, Dick HB. Implantation of a custom intraocular lens with a 30-diopter torus for the correction of high astigmatism after penetrating keratoplasty. J Cataract Refract Surg. 2003;29(12):2444-2447.

5. Borkenstein AFM, Reuland A, Limberger I, Rabsilber TM, Auffarth GU. Transscleral fixation of a toric intraocular lens to correct aphakic keratoplasty with high astigmatism. J Cataract Refract Surg. 2009; 35(5):934-938.

6. Frohn A, Dick HB, Thiel H-J. Implantation of a toric poly(methyl methacrylate) intraocular lens to correct high astigmatism. $J$ Cataract Refract Surg 1999;25(12):1675-1678.
Clinical Optometry

\section{Publish your work in this journal}

Clinical Optometry is an international, peer-reviewed, open access journal publishing original research, basic science, clinical and epidemiological studies, reviews and evaluations on clinical optometry. All aspects of patient care are addressed within the journal as well as the practice of optometry including economic and business analyses. Basic and clinical

Submit your manuscript here: http://www.dovepress.com/clinical-optometry-journal

\section{Dovepress}

research papers are published that cover all aspects of optics, refraction and its application to the theory and practice of optometry. The manuscript management system is completely online and includes a very quick and fair peer-review system, which is all easy to use. Visit http://www.dovepress. com/testimonials.php to read real quotes from published authors. 